\title{
EDUCAÇÃO AMBIENTAL E METODOLOGIA DA PROBLEMATIZAÇÃO APLICADAS AOS PROBLEMAS URBANOS DE CRICIÚMA (SC)
}

\author{
Amanda Bellettini Munari ${ }^{1}$ \\ Gláucia Cardoso de Souza-Dal Bó ${ }^{2}$ \\ Viviane Kraieski de Assunção ${ }^{3}$ \\ Geraldo Milioli 4
}

Resumo: Este relato é resultado de um processo interdisciplinar de ensinoaprendizagem, pautado em uma abordagem teórico-prática de intervenção sobre a realidade; e que admite a Educação Ambiental (EA) como mecanismo vital de transformação social. Tal proposta é fruto das discussões realizadas na disciplina de Educação Ambiental do PPGCA/UNESC, que consistiu em refletir sobre os problemas socioambientais de Criciúma, valendo-se da metodologia da problematização e apontando alternativas exequíveis sob o crivo de diferentes especialidades acadêmicas. A aplicabilidade das alternativas é requisito para validação dessa metodologia, que se justificou na EA como princípio norteador de uma relação mais ética entre a sociedade e o ambiente.

Palavras-chave: Educação Ambiental; Metodologia da Problematização; Criciúma.

1 Doutoranda do Programa de Pós-Graduação em Ciências Ambientais (PPGCA) da Universidade do Extremo Sul Catarinense - UNESC. E-mail: amandabellettini@gmail.com.

2 Doutoranda do Programa de Pós-Graduação em Ciências Ambientais (PPGCA) da Universidade do Extremo Sul Catarinense - UNESC. E-mail: glaudsouza@gmail.com.

3 Professora do Programa de Pós-Graduação em Ciências Ambientais (PPGCA) da Universidade do Extremo Sul Catarinense - UNESC. E-mail: vivianekraieski@gmail.com.

${ }^{4}$ Professor do Programa de Pós-Graduação em Ciências Ambientais (PPGCA) da Universidade do Extremo Sul Catarinense - UNESC. E-mail: gmi@unesc.net.

Revbea, São Paulo, V. 13, № 1: 76-86, 2018. 


\section{Introdução}

Os problemas socioambientais passaram a ganhar notoriedade a partir da década de 1960, chamando a atenção de atores e instituições sociais para a necessidade de reflexão e intervenção sobre o modo como a sociedade estava se relacionando com o ambiente (TREVISOL, 2003). Neste contexto, a Educação Ambiental passou a ser compreendida como um meio de transformação desta realidade, por meio da construção de uma nova ética e visão de mundo (BOFF, 1999), voltadas para o desenvolvimento da sustentabilidade (SACHS, 1986).

A Conferência de Tbilisi, em 1977, representou, indubitavelmente, um marco histórico, por ser dedicada integralmente à discussão da Educação Ambiental, definindo-a como um processo contínuo, inerente à tomada de consciência acerca dos problemas ambientais, seja individual ou coletivamente (TELLES, 2003). Legalmente, no Brasil, a Educação Ambiental é citada como um princípio da Política Nacional de Meio Ambiente (BRASIL, 1981), como processo a ser fomentado em todos os níveis de ensino e também nas comunidades. Ela aparece também na Constituição Federal (BRASIL, 1988), como um instrumento de conscientização pública para a preservação do meio ambiente. A Política Nacional de Educação Ambiental foi instituída no ano de 1999 (BRASIL, 1999), admitindo-a como um processo a ser trabalhado em âmbito formal e não formal.

Para Leff (2001), trata-se de um instrumento de construção da cidadania ambiental e de fomento a uma cultura democrática e participativa, amparado por uma relação ética entre ser humano e meio ambiente. Além de proporcionar a preservação e a conservação ambiental, a Educação Ambiental, ou socioambiental, como se refere Carvalho (2006), deve ir além de promover exclusivamente o uso racional dos recursos naturais. Ribeiro (2009) salienta que já temos a teoria e que sabemos o caminho para um novo desenvolvimento, norteado por princípios mais sustentáveis. Contudo, Silva et al (2011) advertem que se faz necessária uma postura mais ética da sociedade, a partir de uma visão mais ampla e sistêmica dos diversos problemas que acometem o ambiente e, por consequência, as coletividades humanas, e que fomentem ações práticas e exequíveis sob os pontos de vista ambiental, social e econômico.

É consensual entre alguns autores (LEFF, 2001; DIAS, 2004; CARVALHO, 2006), que a Educação Ambiental foi trabalhada durante muito tempo de forma pontual, por meio de uma visão simplista, exclusivamente naturalista ou ecológica. Há diferenças fundamentais entre uma educação conservadora ou conservacionista, que se atém à manutenção da estrutura social vigente e de todos os seus valores econômicos e políticos; e uma educação emancipatória para o meio ambiente, que se dedica a uma profunda mudança desses valores e à construção de uma nova sensibilidade (BRÜGGER, 1994; CRESPO, 1998; LIMA, 2002).

Em detrimento do caráter pontual de atividades de Educação Ambiental, quando realizadas apenas em dias alusivos ao meio ambiente, é preciso 
estimular a participação do público-alvo, fazê-los perceberem-se corresponsáveis do processo educativo, por meio de metodologias alternativas àquelas que se enquadram ou justificam os fins da perspectiva naturalista. Nesse sentido, a metodologia da problematização (BERBEL, 1998) é um instrumento teórico-prático de intervenção sobre a realidade social, que pode ser aplicado em diversas áreas e com diferentes sujeitos. A contribuição principal desta metodologia caracteriza-se pelo enfrentamento de situações-problema e formação de um sujeito mais crítico e sensível à causa ambiental, a partir de uma abordagem mais voltada para uma educação socioambiental e emancipatória.

O presente relato compartilha tanto a metodologia adotada, quanto os resultados de uma experiência vivenciada no âmbito da disciplina de Educação Ambiental do Programa de Pós-Graduação em Ciências Ambientais (PPGCA) da Universidade do Extremo Sul Catarinense (UNESC). A partir da formação de grupos interdisciplinares, valeu-se da metodologia da problematização como fundamento para identificar e apontar soluções para os problemas urbanos da cidade de Criciúma (SC), admitindo a Educação Ambiental como um meio para a compreensão e modificação dos cenários analisados.

A metodologia da problematização é apontada como uma alternativa apropriada para o ensino superior (BERBEL, 1998), de modo que a maioria dos estudos de caso encontrados no banco de dados SCIELO reportam-se ao seu emprego na área da saúde (BERBEL, 1995; MELO et al, 2016), principalmente, no ensino da enfermagem (SCHAURICH; CABRAL; ALMEIDA, 2007; MELO; QUELUCI; GOUVÊA, 2014). Pesquisas que tenham aplicado essa metodologia na área ambiental não foram encontradas no banco de dados mencionado.

Floriani e Knechtel (2003) defendem o uso dessa metodologia como uma alternativa metodológica de ensino e pesquisa para a inserção da dimensão ambiental nas universidades, assim como sugere Berbel (1998), uma vez que a prática interdisciplinar nesse âmbito não tem sido suficientemente compreendida.

\section{Relato}

A metodologia da problematização é originalmente proveniente do método do arco, de Charles Maguerez, cujo esquema foi apresentado por Bordenave e Martins (1982). É constituída por cinco etapas que se desenvolvem a partir da observação da realidade, definição de pontos-chave, teorização, identificação de hipóteses de solução e aplicação à realidade (prática) (Figura 1). Trata-se de uma metodologia tanto de ensino, quanto de estudo e trabalho, passível de ser utilizada oportunamente em situações cujas questões estejam relacionadas com a vida em sociedade (BERBEL, 1998), como é o caso da questão ambiental. 


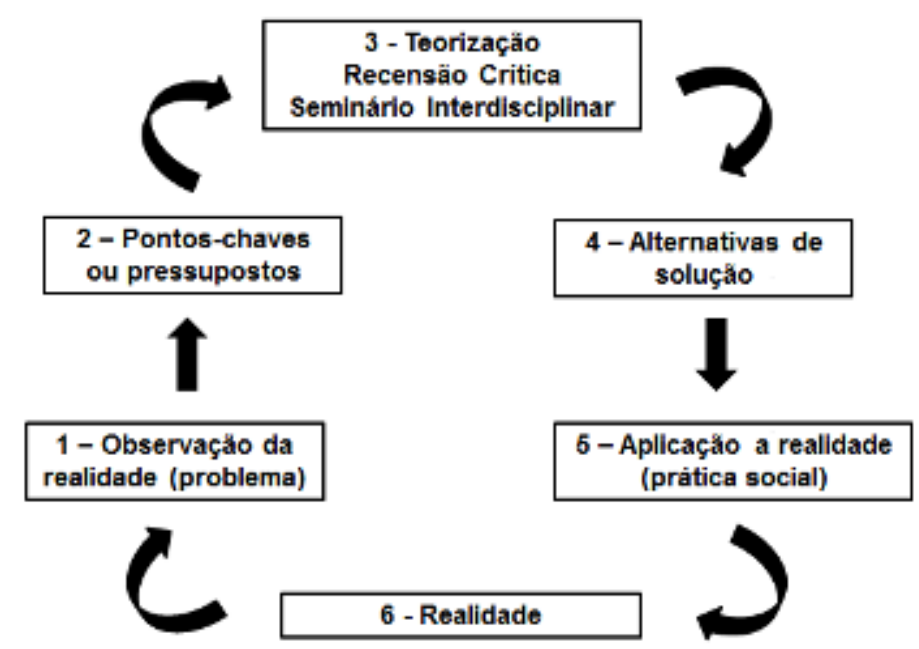

Figura 1: Esquema representativo da metodologia da problematização.

Fonte: Adaptado de BERBEL (1995, p. 11).

Assim, no primeiro encontro da disciplina, os alunos foram apresentados à metodologia de trabalho e convidados a saírem in loco para observação da realidade, apontando os problemas socioambientais urbanos de Criciúma, localizado no sul do Estado de Santa Catarina (Figura 2), e que possui 192.308 habitantes (IBGE, 2010). Criciúma é o principal município da denominada "região carbonífera" catarinense, e já foi considerada a $14^{\mathrm{a}}$ área critica do país mais poluída (VOLPATO, 2001), devido, principalmente, à extração e ao beneficiamento de carvão mineral.

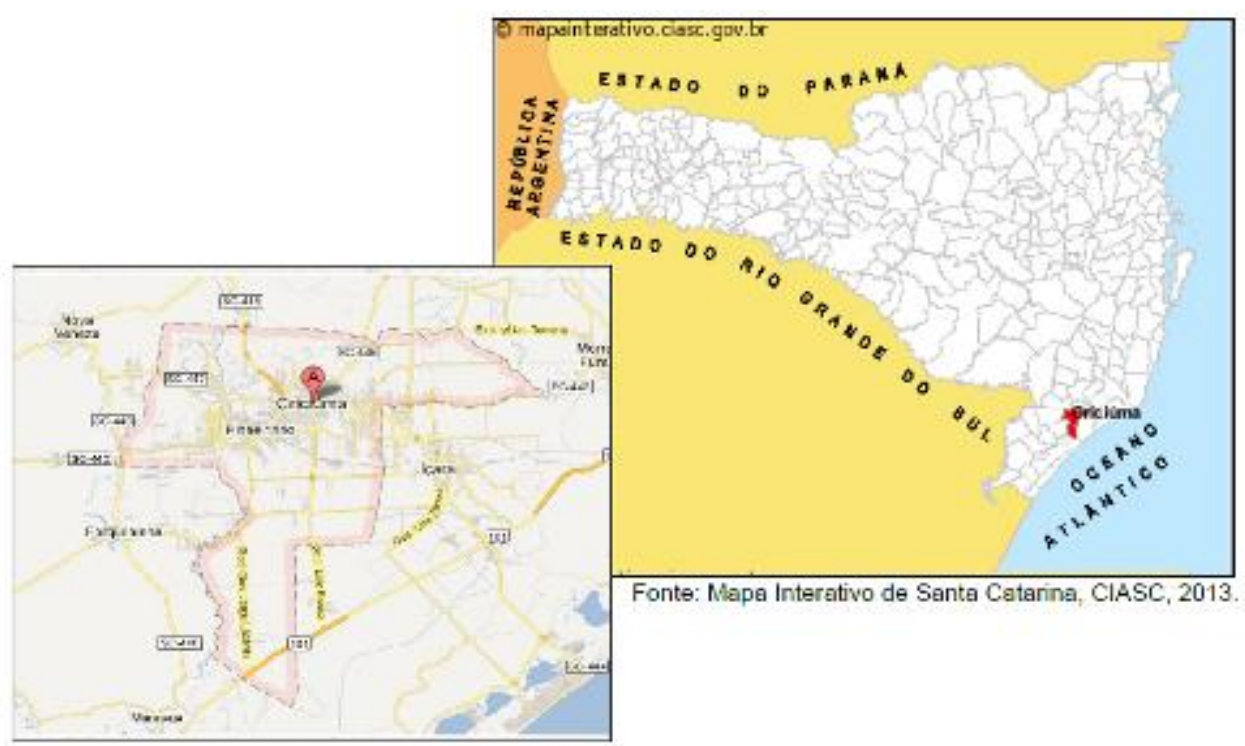

Figura 2: Lócus de estudo: a cidade de Criciúma (SC).

Fonte: SEBRAE/SC (2013, p. 11).

A turma foi dividida em equipes e orientada a perceber e registrar atentamente problemas ou situações que, por algum motivo, despertaram a sua 
atenção. O registro foi feito por meio de fotografias (Figura 3) e anotações em diários de campo.

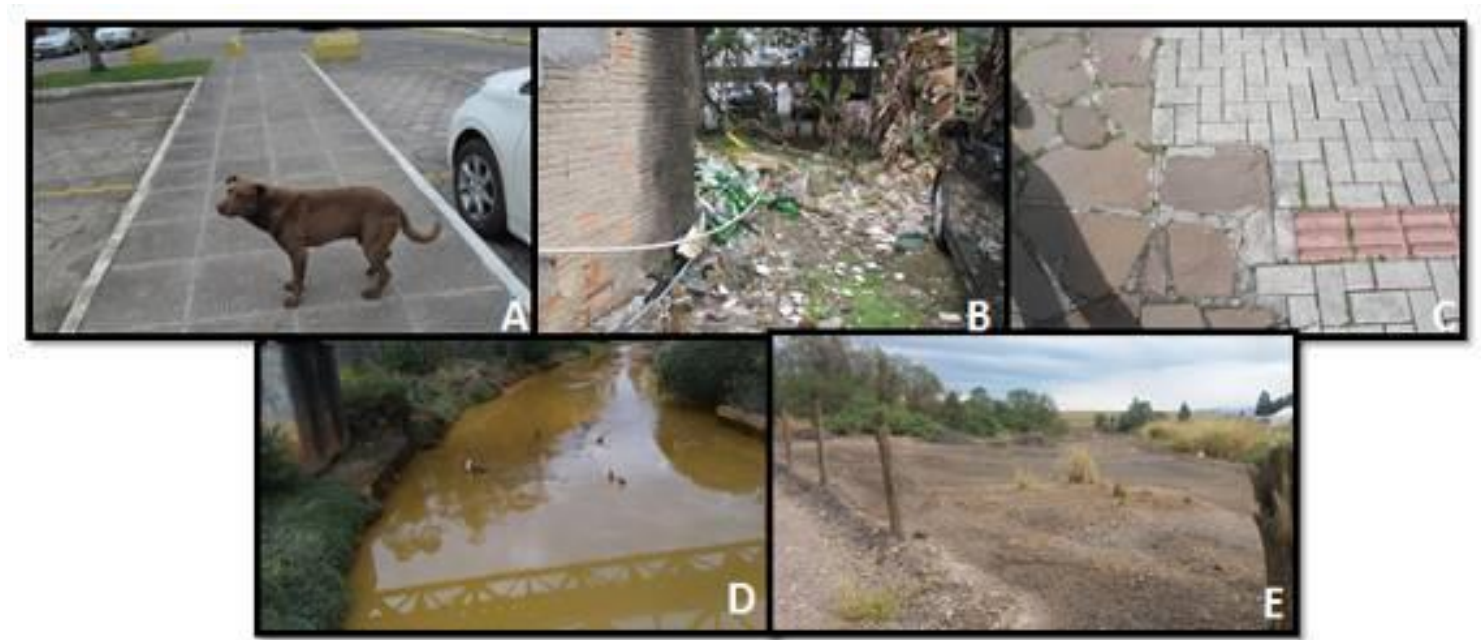

Figura 3: Problemas registrados pelos alunos. Foto A: Abandono de animais; Foto B: Disposição de resíduos; Foto C: Acessibilidade; Foto D: Rio Criciúma; Foto E: Mineração de carvão.

Fonte: dos Alunos (2017).

É importante mencionar as diferentes áreas de formação dos alunos envolvidos - advogados, biólogos, engenheiros, educador, psicólogo, administrador - e a importância da contribuição interdisciplinar para a qualificação de todo o processo de construção do conhecimento.

$\mathrm{Na}$ sequência, todas as equipes fizeram uma exibição do material coletado e relataram as situações vivenciadas, compartilhando com o grande grupo as principais problemáticas encontradas. A partir da reflexão e discussão sobre as causas e agravantes de tais problemas, foram definidos coletivamente, dentre tantos pontos levantados e analisados, quais deveriam ser trabalhados com maior detalhamento pelas equipes. Foram apontados cinco temas ou palavras-chave (Quadro 1).

Quadro 1: Identificação dos pontos-chave a partir da observação da realidade.

\begin{tabular}{|c|l|l|}
\hline Equipe & \multicolumn{1}{|c|}{ Pontos-chave } & Formação acadêmica dos componentes \\
\hline 1 & Abandono de animais não humanos & $\begin{array}{l}\text { Engenheiro ambiental, biólogo, bacharel } \\
\text { em direito. }\end{array}$ \\
\hline 2 & Destinação inadequada de resíduos & $\begin{array}{l}\text { Bacharel em educação física, biólogo, } \\
\text { psicólogo }\end{array}$ \\
\hline 3 & $\begin{array}{l}\text { Falta de acessibilidade dos espaços } \\
\text { públicos }\end{array}$ & $\begin{array}{l}\text { Bacharel em direito, biólogo, engenheiro } \\
\text { ambiental }\end{array}$ \\
\hline 4 & $\begin{array}{l}\text { Contaminação das águas do Rio } \\
\text { Criciúma }\end{array}$ & Biólogo, bacharel em direito, jornalista \\
\hline 5 & $\begin{array}{l}\text { Consequências da mineração de } \\
\text { carvão }\end{array}$ & Administrador, biólogo, bacharel em direito \\
\hline
\end{tabular}

Fonte: dos Autores.

$\mathrm{Na}$ fase seguinte, deu-se a teorização, que consistiu na realização de uma pesquisa bibliográfica para fundamentar teoricamente e contextualizar os Revbea, São Paulo, V. 13, № 1: 76-86, 2018. 
dados e as informações, quantitativos ou qualitativos, relativos de cada pontochave. Afinal, o apontamento de soluções, considerando a complexidade e o encadeamento dos problemas, implica um aprofundamento do conhecimento sobre os assuntos abordados, para interferir da melhor forma possível sobre a realidade. Os participantes foram orientados a pesquisar em acervos físicos e virtuais, desde que de procedência conhecida no meio científico. Compreenderam as principais fontes de busca: livros, periódicos especializados, anais de congressos, atas de encontros específicos, etc.

Desse modo, cada equipe elaborou uma resenha sobre o seu tema, que foi compartilhada com o grande grupo. Com o propósito de socializar e aprofundar os aspectos teóricos de cada tema, as equipes apresentaram um seminário, a partir do qual foram definidas as hipóteses de solução, bem como os meios de colocá-las em prática. A última etapa exigiu mais do que um exercício teórico dos alunos, já que eles deveriam justificar a aplicabilidade das soluções elencadas.

Assim, uma vez levantados os problemas e munidos de conhecimento teórico sobre tais temas, puderam ser apontadas, sob o crivo de diferentes especialidades acadêmicas, soluções efetivamente exequíveis para resolvê-los ou minimizá-los. Partiu-se de uma realidade social e, ao final, chegou-se ao caminho pelo qual essa realidade poderia ser melhorada ou transformada (Quadro 2).

Quadro 2 - Pontos-chave e síntese da teorização e soluções apresentadas por cada equipe.

\begin{tabular}{|c|c|c|}
\hline Ponto-chave & Teorização do tema & Soluções apresentadas \\
\hline $\begin{array}{l}\text { Abandono de } \\
\text { animais não } \\
\text { humanos }\end{array}$ & $\begin{array}{l}\text { Problematizou os efeitos perversos do } \\
\text { descarte e objetificação da vida } \\
\text { (SINGER, 2004), com a exploração do } \\
\text { mercado animal em pet shops, e a } \\
\text { invisibilidade das raças não definidas } \\
\text { (vulgo "vira-latas"). Também tratou sobre } \\
\text { a saúde pública, evidenciando as } \\
\text { zoonoses que podem ser transmitidas } \\
\text { por cães e gatos abandonados. }\end{array}$ & $\begin{array}{l}\text { - Registro e identificação dos animais } \\
\text { abandonados; } \\
\text { - Realização de um programa de } \\
\text { castração gratuita; } \\
\text { - Desenvolvimento de um programa } \\
\text { de educação sobre posse } \\
\text { responsável. }\end{array}$ \\
\hline $\begin{array}{l}\text { Destinação } \\
\text { inadequada de } \\
\text { resíduos }\end{array}$ & $\begin{array}{l}\text { Identificou que os resíduos sólidos } \\
\text { domiciliares são coletados por uma } \\
\text { empresa contratada pela prefeitura } \\
\text { municipal e a fração reciclável fica a } \\
\text { cargo do Programa de Coleta Seletiva, } \\
\text { sendo encaminhada para dois } \\
\text { empreendimentos solidários de } \\
\text { catadores. O órgão ambiental municipal } \\
\text { desenvolve um programa de Educação } \\
\text { Ambiental, e a UNESC, por meio do } \\
\text { Projeto de Extensão "Coleta Seletiva } \\
\text { Solidária" também é fomentadora de um } \\
\text { novo cenário em relação à coleta } \\
\text { seletiva na cidade e a melhores } \\
\text { condições de trabalho e de vida aos } \\
\text { catadores. }\end{array}$ & $\begin{array}{l}\text { - Viabilização de condições mais } \\
\text { dignas de trabalho aos catadores, } \\
\text { buscando maior apoio operacional e } \\
\text { financeiro para catadores da } \\
\text { prefeitura; } \\
\text { - Criação e desenvolvimento efetivo } \\
\text { de um programa de Educação } \\
\text { Ambiental para sensibilizar a } \\
\text { população para o consumo } \\
\text { consciente e o descarte mais } \\
\text { adequado dos resíduos, de modo a } \\
\text { potencializar a coleta seletiva. } \\
\text { - Implementação do Plano Municipal } \\
\text { de Gerenciamento dos Resíduos } \\
\text { Sólidos, por meio da instituição de } \\
\text { uma lei municipal. }\end{array}$ \\
\hline
\end{tabular}

Continua... 
...continuação.

\begin{tabular}{|c|c|c|}
\hline $\begin{array}{c}\text { Falta de } \\
\text { acessibilidade } \\
\text { do espaço } \\
\text { urbano }\end{array}$ & $\begin{array}{l}\text { Contribuiu para a caracterização da } \\
\text { infraestrutura urbana da cidade de } \\
\text { Criciúma como deficitária, tanto em } \\
\text { termos de traçado urbano, como pela } \\
\text { falta de espaços públicos e de } \\
\text { efetivação de políticas públicas } \\
\text { urbanas. Um estudo sobre a história } \\
\text { do desenvolvimento da cidade } \\
\text { revelou que esta cresceu a partir das } \\
\text { vilas operárias em torno das minas de } \\
\text { carvão, de modo que não houve } \\
\text { nenhuma forma de planejamento } \\
\text { urbano. Também ressaltou a função } \\
\text { social das calçadas, que representam } \\
\text { a possibilidade de espaços de } \\
\text { convivência, de trocas, encontros, } \\
\text { com a finalidade de contribuir para o } \\
\text { fortalecimento da urbanidade. }\end{array}$ & $\begin{array}{l}\text { - Planejamento e execução de } \\
\text { pavimentações que contemplem } \\
\text { ciclovias, faixas de pedestres e } \\
\text { sinalização adequada; } \\
\text { - Sensibilização da população para } \\
\text { apropriação e manutenção de } \\
\text { espaços públicos } \\
\text { - Divulgação de leis que tratem da } \\
\text { inclusão e acessibilidade, como a } \\
\text { Lei n. 10.098/94, que estabelece } \\
\text { critérios básicos para a promoção } \\
\text { da acessibilidade de pessoas com } \\
\text { deficiência ou com mobilidade } \\
\text { reduzida. } \\
\text { - Implementação efetiva da } \\
\text { legislação local que responsabilize } \\
\text { os munícipes pela edificação do } \\
\text { passeio público dentro das normas } \\
\text { de acessibilidade, com maior } \\
\text { fiscalização na padronização de } \\
\text { calçadas. }\end{array}$ \\
\hline $\begin{array}{l}\text { Contaminação } \\
\text { das águas do } \\
\text { Rio Criciúma }\end{array}$ & $\begin{array}{l}\text { Revelou os usos dispensados ao Rio } \\
\text { Criciúma ao longo das várias } \\
\text { décadas de história da cidade, } \\
\text { incluindo, principalmente, a lavagem } \\
\text { do carvão, o esgotamento industrial e } \\
\text { doméstico. O rio também apresenta } \\
\text { problemas decorrentes da exploração } \\
\text { mineral de outras matérias-primas. }\end{array}$ & $\begin{array}{l}\text { - Recomposição das margens e } \\
\text { nascentes, bem como do canal de } \\
\text { drenagem, garantindo o recuo legal } \\
\text { e recompondo os ambientes } \\
\text { intensamente degradados. } \\
\text { - Envolvimento direto da população } \\
\text { na gestão do território urbano, com } \\
\text { estímulo à adoção de medidas } \\
\text { pontuais, como captação de água } \\
\text { da chuva, utilização de torneiras } \\
\text { que economizam mais água e } \\
\text { evitam o desperdício por } \\
\text { gotejamento; a reutilização de água } \\
\text { cinza (água da máquina de lavar) } \\
\text { para uso em banheiro e a lavação } \\
\text { de calçadas. }\end{array}$ \\
\hline $\begin{array}{c}\text { Consequências } \\
\text { da mineração } \\
\text { de carvão }\end{array}$ & $\begin{array}{l}\text { Ateve-se ao levantamento de dados } \\
\text { sobre a água e do solo e à } \\
\text { problemática do depósito de rejeitos } \\
\text { no município. } \\
\text { Foi investigado o andamento da Ação } \\
\text { Civil Pública e do Termo de } \\
\text { Ajustamento de Conduta, que obrigou } \\
\text { as carboníferas e a União a } \\
\text { desenvolverem maior controle } \\
\text { ambiental de todo seu processo } \\
\text { produtivo e a recuperação do passivo } \\
\text { ambiental. }\end{array}$ & $\begin{array}{l}\text { - Implementação, a curto prazo, } \\
\text { programas efetivos de recuperação } \\
\text { de áreas degradas na região; } \\
\text { - Transformação das áreas } \\
\text { recuperadas em áreas de lazer; } \\
\text { - Promoção de debate amplo e } \\
\text { constante sobre os problemas } \\
\text { socioambientais da região, visando } \\
\text { maior cumprimento da legislação } \\
\text { ambiental por todos os setores; } \\
\text { - Planejamento do desenvolvimento } \\
\text { da cidade de maneira sustentável, } \\
\text { a partir do levantamento dos } \\
\text { desafios e possibilidades. }\end{array}$ \\
\hline
\end{tabular}

Fonte: dos Autores.

Revbea, São Paulo, V. 13, № 1: 76-86, 2018. 
Por fim, após a socialização dos resultados finais desenvolvidos por cada equipe, as equipes foram estimuladas a apresentar estes resultados em outros espaços, por meio da participação dos estudantes em eventos acadêmicos, divulgação na imprensa local dos dados levantados e publicação de partes da pesquisa desenvolvida em periódicos qualificados.

\section{Discussão}

A metodologia da problematização, aqui utilizada como mediadora de um processo de ensino-aprendizagem na pós-graduação, permite tanto a mobilização dos repertórios já trazidos pelos alunos, provenientes de suas formações específicas e do aprendizado construído em outras disciplinas cursadas no programa de pós-graduação, quanto a construção e o aprofundamento do conhecimento sobre os temas elencados, por meio do estudo de referenciais teóricos relacionados aos problemas socioambientais.

Deste modo, pode-se compreender que a metodologia da problematização desenvolve a autonomia (FREIRE, 1996) dos alunos, pois parte de sua própria percepção sobre a realidade socioambiental, estimulando seu protagonismo na seleção do material a ser estudado e na construção das soluções para os problemas selecionados. Neste sentido, cada aluno torna-se um sujeito ativo na construção do próprio conhecimento, ao mesmo tempo em que também contribui para o processo de ensino-aprendizagem dos colegas por meio do desenvolvimento do trabalho coletivo.

Ao se partir da percepção dos problemas socioambientais urbanos do município de Criciúma, buscou-se uma compreensão estendida do conceito de meio ambiente - definindo-o em suas dimensões naturais ou biológicas, socioculturais, econômicas e políticas. Deste modo, possibilita-se romper com a noção restrita de meio ambiente associada apenas às áreas verdes (matas e florestas), contemplando também o ambiente construído, ao mesmo tempo em que se empreende um movimento de problematização da realidade local, próxima dos estudantes.

A teorização e as soluções apresentadas por cada equipe demonstram a variedade de fontes consultadas, em diversas áreas de conhecimento, como a engenharia, ciências biológicas, direito, psicologia, educação física, dentre outras, assim como a complexidade das soluções desenvolvidas. Todos os temas elencados exigiram das equipes um maior conhecimento sobre a cidade de Criciúma, desde sua formação histórica e econômica até o estágio atual da contaminação das águas, do passivo ambiental da exploração de carvão e da legislação referente à acessibilidade urbana e aos resíduos sólidos.

Compreende-se que a metodologia proposta fomenta um aprendizado sobre a interdisciplinaridade, um dos princípios norteadores da Educação Ambiental, conforme a legislação brasileira (BRASIL, 1999) e declarações internacionais, como a de Tbilisi, Toronto, Rio 92, dentre outras. Primeiramente, a formação de equipes com alunos com formações disciplinares distintas os induz a trabalhar de forma conjunta em todas as etapas da disciplina - desde a

revista brasileira educação ambiental 
observação da realidade até a construção das soluções para os problemas socioambientais. Por fim, o resultado final reafirma a própria importância da interdisciplinaridade, já que as soluções demonstram a necessidade de medidas em múltiplas dimensões, tanto técnicas quanto políticas e sociais.

Dentre as soluções apresentadas, destaca-se a importância atribuída à Educação Ambiental, por, pelo menos, duas equipes, o que pode ser compreendida como um reconhecimento dos alunos sobre o papel da Educação Ambiental na transformação da realidade socioambiental. Outras equipes referiram-se à participação efetiva da população para solução dos problemas socioambientais, o que remete à gestão integrada e participativa, reiterada em diversas legislações ambientais brasileiras.

Neste sentido, as equipes apresentaram, por meio das soluções desenvolvidas, a importância de se compreender o papel dos sujeitos como cidadãos, cientes de seus direitos e deveres, que devem atuar, ao mesmo tempo, de forma individual e coletiva, o que reflete os princípios que norteiam a Educação Ambiental (BRASIL, 1999). Desta maneira, a solução dos problemas socioambientais exige tanto atuações individualizadas, com a adoção de medidas pontuais no cotidiano, quanto a participação política, pautando o poder público quanto a criação e implementação de leis e projetos que visem à melhoria da qualidade ambiental e de vida da população.

\section{Considerações Finais}

A exigência legal de incluir a Educação Ambiental em todos os níveis de ensino passou a demandar que educadores desenvolvam não apenas uma maior sensibilidade à questão ambiental, como a utilização de metodologias que contribuam para a formação de sujeitos ecológicos (CARVALHO, 2006). A experiência de aplicação da metodologia da problematização na disciplina Educação Ambiental, oferecida no Programa de Pós-Graduação em Ciências Ambientais (PPGCA) da UNESC, possibilitou um levantamento de problemas socioambientais urbanos existentes no município de Criciúma, bem como de soluções que poderiam minimizá-los ou saná-los. A proposta de uma saída de campo, com itinerários definidos por cada equipe, e o contato com a literatura acadêmica sobre os temas elencados também constituíram ferramentas fundamentais na construção coletiva do conhecimento, possibilitando uma investigação mais eficiente e uma análise crítica dos assuntos tratados.

Percebeu-se que os problemas levantados, num sentido mais profundo, são originados do modelo de sociedade em que nos encontramos. Por meio da percepção destes problemas, os estudantes puderam aproximar-se, a partir de um novo olhar, do meio ambiente urbano de Criciúma, prospectando também alternativas. Com a aplicação da metodologia da problematização, a Educação Ambiental pode atuar em uma perspectiva mais complexa, para além de um tratamento naturalista ou puramente biologizante, contemplando o meio ambiente em suas múltiplas dimensões e uma visão integradora entre ser humano e natureza. 


\section{Referências}

BERBEL, N. N. Metodologia da problematização: uma alternativa metodológica apropriada para o ensino superior. Semina: Ciências Sociais e Humanas, Londrina, v. 16, n. 2, ed. especial, p. 9-19, outubro 1995.

BERBEL, N. N. "Problematization" and Problem-Based Learning: different words or different ways? Interface - Comunicação, Saúde, Educação, v.2, n. 2, 1998.

BORDENAVE, J. D; MARTINS, P. A. Estratégias de ensino aprendizagem. $4^{a}$ ed. Petrópolis: Vozes, 1982.

BRASIL. Constituição 1988. Brasília: Senado Federal, 2000.

BRASIL. Lei n. 6.938, de 31 de agosto de 1981. Institui a Política Nacional do Meio Ambiente e dá outras providências. Disponível em: $<$ http://www.planalto.gov.br/ccivil 03/Leis/L6938.htm>. Acesso em: 31 mar. 2017.

BRASIL. Lei n. 9.795, de 27 de abril de 1999. Institui a Política Nacional de Educação Ambiental. Disponível em: <http://www.planalto.gov.br/ccivil 03/Leis/L9795.htm>. Acesso em: 31 mar. 2017.

BOFF, L. A ética da vida. São Paulo: Letraviva, 1999.

BRÜGGER, P. Educação ou adestramento ambiental. Florianópolis: Letras Contemporâneas, 1994.

CARVALHO, I.C.M. Educação Ambiental: a formação do sujeito ecológico. $2^{a}$ ed. São Paulo: Cortez, 2006.

CRESPO, S. Educar para a sustentabilidade: a Educação Ambiental no programa da agenda 21. In: NOAL, F.O.; REIGOTA, M.; BARCELOS, V.H.L. (Org.) Tendências da Educação Ambiental brasileira. Santa Cruz do Sul: EDUNISC, 1998. p. 211-226.

DIAS, G.F. Ecopercepção: um resumo didático dos desafios socioambientais. São Paulo: Gaia, 2004.

FLORIANI, D.; KNECHTEL, M.R. Educação Ambiental, Epistemologias e Metodologias. Curitiba: Vicentina, 2003.

FREIRE, P. Pedagogia da autonomia: Saberes necessários à prática educativa. Rio de Janeiro: Editora Paz e Terra, 1996.

IBGE - Instituto Brasileiro de Geografia Estatística. Censo 2010. Disponível em: <https://censo2010.ibge.gov.br/>. Acesso em: 31 mar. 2017.

LEFF, E. Saber Ambiental: Sustentabilidade, racionalidade, complexidade, poder. 3a ed. Petrópolis, RJ: Vozes, 2001.

LIMA, G.F.C. Crise ambiental, educação e cidadania: os desafios da sustentabilidade emancipatória. In: BAETA, A.M.B. et al. (Org.) Educação Ambiental: repensando o espaço da cidadania. São Paulo: Cortez, 2002. p. 109-142. 
MELO, M.C.; QUELUCI, G.C.; GOUVEA, M.V. Problematizing the multidisciplinary residency in oncology: a practical teaching protocol from the perspective of nurse residents. Revista Escola Enfermagem USP[online], v. 48, n. 4, p. 706-714, agosto 2014.

MELO, R.H.V. Roda de Conversa: uma Articulação Solidária entre Ensino, Serviço e Comunidade. Revista Brasileira de Educação Médica, Rio de Janeiro, v. 40, n. 2, p. 301-309, abril-junho 2016.

RIBEIRO, M.A. Ecologizar: vol 1 - princípios para a ação. 4a ed. Brasília: Editora Universa, 2009.

SACHS, I. Ecodesenvolvimento: Crescer sem Destruir. São Paulo: Vértice, 1986.

SCHAURICH, D.; CABRAL, F.B.; ALMEIDA, M.A. Metodologia da problematização no ensino em Enfermagem: uma reflexão do vivido no PROFAE / RS. Esc. Anna Nery [online], v. 11, n. 2, p. 318-324, junho 2007.

SEBRAE - SERVIÇO DE APOIO ÀS MICRO E PEQUENAS EMPRESAS. Santa Catarina em números. Florianópolis: SEBRAE/SC, 2013.

SILVA, A.D.V.; SILVA, A.D.V.; MENDONÇA, A.W.; MARCOMIN, F.E.; MAZZUCO, K.T.M.; BECKER, R.R. Percepção Ambiental como ferramenta para processos de Educação Ambiental na Universidade. Revista eletrônica Mestrado Educação Ambiental, v. 27, julho-dezembro 2011.

SINGER, P. Libertação animal. Porto Alegre: Lugano, 2004.

TELLES, M.Q. Vivências integradas com o meio ambiente: práticas de Educação Ambiental para escolas, parques, praças e zoológicos. São Paulo: Sá Editora, 2003.

TREVISOL, J.V. A Educação Ambiental em uma sociedade de risco: tarefas e desafios na construção da sustentabilidade. Joaçaba: UNOESC, 2003.

VOLPATO, T.G. Vidas Marcadas: trabalhadores do carvão. Tubarão: Unisul, 2001. 